\title{
Dietary antioxidant supplementation reduces lipid peroxidation but impairs vascular function in small mesenteric arteries of the streptozotocin-diabetic rat
}

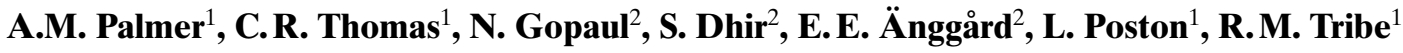 \\ ${ }^{1}$ United Medical and Dental Schools, St Thomas' Hospital, London, UK \\ ${ }^{2}$ The William Harvey Research Institute, London, UK
}

\begin{abstract}
Summary Impaired endothelium-dependent relaxation could underlie many of the vascular complications associated with insulin-dependent diabetes mellitus, and may be mediated by increased oxidative stress. The effect of antioxidants on vascular endothelial function and oxidative stress of streptozotocin-diabetic rats was assessed by dietary supplementation with vitamins $\mathrm{E}$ and C. Diabetic (i.v. streptozotocin, $45 \mathrm{mg} / \mathrm{kg}$ ) male Sprague-Dawley rats were fed one of six supplemented diets containing 75.9, 250, or $500 \mathrm{mg}$ vitamin $\mathrm{E} / \mathrm{kg}$ chow, $250 \mathrm{mg}$ vitamin $\mathrm{C} / \mathrm{kg} \mathrm{H}_{2} \mathrm{O}$, $250 \mathrm{mg}$ vitamin $\mathrm{E} / \mathrm{kg}$ chow plus $250 \mathrm{mg}$ vitamin $\mathrm{C} / \mathrm{kg}$ $\mathrm{H}_{2} \mathrm{O}$, or chow deficient in vitamin $\mathrm{E}$, and then compared to standard-fed control rats. After 4 weeks, small mesenteric arteries were dissected and mounted on a small vessel myograph, concentration response curves were then constructed to noradrenaline, acetylcholine and sodium nitroprusside. Acetylcholinemediated relaxation was impaired in arteries from di-
\end{abstract}

abetic rats $\left(\mathrm{pEC}_{50} 6.701 \pm \mathrm{SEM} 0.120, n=8\right)$ compared to controls $(7.386 \pm 0.078, n=6 ; p<0.05)$. The $500 \mathrm{mg} / \mathrm{kg}$ vitamin $\mathrm{E}$ diet further impaired maximum relaxation to acetylcholine $(58.2 \pm 10.5$ vitamin $\mathrm{E}$, $n=7$ vs $84.4 \pm 5.3 \%$ standard, $p<0.05)$, and the combined vitamin $\mathrm{E}$ plus $\mathrm{C}$ diet impaired maximum relaxation to sodium nitroprusside $(48.5 \pm 4.1$ in vitamin $\mathrm{E}+\mathrm{C}, n=8$ vs $75.6 \pm 3.9 \%$ standard; $p<0.01)$. However, plasma 8-epi-prostaglandin $(\mathrm{PG}) \mathrm{F}_{2} \alpha$ (measured as an estimate of oxidative stress) was dose-dependently decreased in rats on vitamin E supplemented diets. Dietary antioxidant supplementation did not reverse impaired endothelial function in this model of uncontrolled diabetes despite a concomitant decrease in oxidative stress. [Diabetologia (1998) 41:148-156]

Keywords Vitamin E, ascorbic acid, oxidative stress, isoprostanes, nitric oxide, vascular endothelium, resistance artery, diabetes mellitus.
Insulin-dependent diabetes mellitus (IDDM) is associated with abnormal function of the vascular endothelium and it is proposed that this defect could underlie many of the associated vasculopathies [1]. Studies from our laboratory and others have reported impaired vasodilatory responses to the endothelium-dependent vasodilator acetylcholine $(\mathrm{ACh})$ in

Received: 8 July 1997 and in revised form: 29 September 1997

Corresponding author: Dr. R. M. Tribe, Department of Obstetrics and Gynaecology, St Thomas' Hospital, Lambeth Palace Road, London SE1 7EH, UK

Abbreviations: ACh, Acetylcholine; NA, noradrenaline; SNP, sodium nitroprusside; IDDM, insulin-dependent diabetes mellitus; 8-epi-PGF $\mathrm{PG}_{2} \alpha$, 8-epi-prostaglandin $\mathrm{F}_{2} \alpha$; $\mathrm{NO}$, nitric oxide. isolated arteries from diabetic subjects [2] and in mesenteric [3], femoral [4] and aortic [5] arteries from the streptozotocin (STZ)-diabetic rat (an animal model of uncontrolled IDDM). Although a physiological endothelium-dependent dilatory role of ACh has sometimes been questioned, the reduced relaxation of arteries from diabetic animals to other endothelium-dependent dilators [1] and to increasing luminal flow [6] would suggest that the poor ACh responses reflect a generalised endothelial defect. The abnormal ACh response is likely to result from either decreased nitric oxide (NO) synthesis or increased NO degradation [3, 4]. Several mechanisms have been hypothesised, among which is the suggestion that oxidative stress could play an important role $[7,8]$. 
Oxidative stress may occur as a result of increased free radical generation, decreased levels of antioxidants and/or impaired regeneration of reduced forms of antioxidants. Evidence for oxidative stress in diabetes includes observations of decreased antioxidant plasma concentrations in both diabetic subjects [9] and animal models of diabetes [10], and reports of increased free radical-generated plasma lipid peroxides [11]. There are studies, however, which suggest that vitamin E plasma and tissue levels may be raised in both IDDM [12] and the STZ rat [13], possibly as a compensatory response to increased free radical lipid peroxidation. Free radicals may be responsible for damage to DNA, oxidative modification of lipids including low-density lipoprotein (LDL), and have been implicated in glycation and protein modification reactions that contribute to tissue damage in diabetes [14]. LDL in its native or oxidised state can impair endothelium-dependent relaxation [15], and oxidised LDL may be toxic to cells [11] and decrease expression of endothelial NO-synthase [16]. Lipid peroxidation resulting from oxidative stress may be assessed by measurement of the recently described $\mathrm{F}_{2}$-isoprostanes [17]. These free radical-catalysed isomers of arachidonic acid are stable products of lipid peroxidation which are present in human plasma and are excreted in the urine [18]. Concentrations of the isoprostane, 8 -epi-prostaglandin $(\mathrm{PG}) \mathrm{F}_{2 \alpha}$, are raised in the plasma of non-insulin-dependent diabetic subjects [19] and in heavy smokers [20]. In addition, 8-epi$\mathrm{PGF}_{2 \alpha}$ is a potent constrictor of the coronary circulation [21].

Theoretically, therefore, antioxidant supplementation may be of benefit to vascular function in diabetes. In the Cambridge Heart Antioxidant Study (CHAOS), vitamin $\mathrm{E}$ supplementation has been shown to be of some benefit in non-diabetic patients with coronary artery disease as it decreased the rate of non-fatal myocardial infarction [22]. Some therapeutic potential for dietary antioxidant supplementation has also been inferred from studies of conduit arteries $[5,23]$ and of sciatic nerve endoneurial blood flow in animal models of diabetes [24].

The aim of this study was to determine whether this beneficial effect of antioxidant dietary supplementation on vascular function also occurs in isolated small arteries in an animal model of diabetes. A combination of vitamin $\mathrm{E}$ with vitamin $\mathrm{C}$ was chosen since vitamin $\mathrm{C}$, as well as being a free radical scavenger, also regenerates vitamin $\mathrm{E}$ to its active form [25]. The effect of dietary vitamin $\mathrm{E}$ and $\mathrm{C}$ supplementation on STZ-rat mesenteric small artery function was investigated, and liver and plasma content of vitamin $\mathrm{E}$ after dietary supplementation were measured. Plasma and liver concentrations of 8 -epi- $\mathrm{PGF}_{2 \alpha}$ were estimated in each group of animals as an indicator of oxidative stress.

\section{Materials and methods}

The animal procedures in the following protocol were carried out under Home Office (UK) license number PPL 90 764, and the 'Principles of laboratory animal care' (NIH publication No. 85-23, revised 1985) were followed.

Induction of experimental diabetes. Diabetes was induced in male Sprague-Dawley rats (250-300 g) by caudal intravenous injection of STZ $(45 \mathrm{mg} / \mathrm{kg})$ dissolved in citrate buffer $(0.1 \mathrm{~mol} / \mathrm{l}$ trisodium citrate, $0.1 \mathrm{~mol} / \mathrm{l}$ citric acid). Control animals were injected with vehicle alone. Development of diabetes was confirmed by the presence of glycosuria 3 days after injection. In the fifth week after injection animals were killed by inhalation of $\mathrm{CO}_{2}$ and cervical dislocation. Cardiac puncture was performed to obtain blood samples for the measurement of plasma glucose with an enzymatic ultra violet test, using an HK/G6P-DH method (Cobas Fara Centrifugal analyser; Roche Diagnostic Systems, Welwyn Garden City, UK). Animals were housed individually and provided with food and water ad libitum.

Dietary protocol. The animals were divided into seven groups and supplemented diets commenced 3 days after injection of either STZ or vehicle. Groups 1 and 2 were fed standard diet (75.9 mg vitamin E/kg chow): 1) control non-diabetic rats $(n=6) ; 2)$ diabetic rats $(n=8)$.

The remaining groups of diabetic rats were fed the following supplemented diets: 3) $250 \mathrm{mg}$ vitamin $\mathrm{E} / \mathrm{kg}$ chow $(n=6)$; 4) $500 \mathrm{mg}$ vitamin $\mathrm{E} / \mathrm{kg}$ chow $(n=7) ; 5)$ vitamin $\mathrm{E}$ deficient chow $(n=6)$; 6) $250 \mathrm{mg}$ vitamin $\mathrm{C} / \mathrm{kg}$ drinking water, and standard diet $(n=6)$;

7) $250 \mathrm{mg}$ vitamin $\mathrm{C} / \mathrm{kg}$ drinking water $+250 \mathrm{mg}$ vitamin $\mathrm{E} / \mathrm{kg}$ chow $(n=8)$.

Weight of food consumed and animal weight were recorded twice weekly, and concentration of vitamin $\mathrm{C}$ was based on the observed daily consumption of approximately $500 \mathrm{ml} \mathrm{H}_{2} \mathrm{O}$ per rat. In addition, a group of control non-diabetic animals $(n=6)$ were fed $500 \mathrm{mg}$ vitamin E/kg supplemented diet, and vascular function compared with the control animals on standard chow from group 1.

Assessment of vascular function. The small intestine and intact mesentery were removed from the animal and placed in cold physiological salt solution (PSS) [(mmol/l): $119 \mathrm{NaCl} ; 25 \mathrm{NaH}-$ $\mathrm{CO}_{3}$; 5.5 D-glucose; $1.18 \mathrm{KH}_{2} \mathrm{PO}_{4} ; 1.17 \mathrm{MgSO}_{4} ; 4.7 \mathrm{KCl}$; $2.5 \mathrm{CaCl}_{2} ; 0.026$ EDTA, ethylenediamine-tetra-acetic acid disodium salt]. Third-order branches of the mesenteric tree were dissected free of connective tissue and mounted in pairs as ring preparations on a small vessel myograph for the measurement of isometric tension. The methods have been described in detail previously $[3,26]$. Briefly, arteries were bathed in PSS, gassed with $5 \% \mathrm{CO}_{2} / 95 \% \mathrm{O}_{2}$ at $37^{\circ} \mathrm{C}(\mathrm{pH} 7.45)$, and their passive tension and internal circumference determined. The arteries were then set to an internal circumference equivalent to $90 \%$ of that which they would experience when relaxed in situ under a transmural pressure of $100 \mathrm{mmHg}$ (the maximum active tension for the minimum resting tension is developed at approximately this circumference). Arteries were then subjected to a routine 'run-up' procedure including a total of five contractions to noradrenaline (NA, $5 \mu \mathrm{mol} / \mathrm{l}$ ), $125 \mathrm{mmol} / \mathrm{l}$ potassium solution (KPSS; PSS with equimolar substitution of $\mathrm{KCl}$ for $\mathrm{NaCl}$ ) and $5 \mu \mathrm{mol} / \mathrm{l} \mathrm{NA}$ in KPSS. In the fifth contraction, arteries that reached an effective pressure of $100 \mathrm{mmHg}$ 
$(13.3 \mathrm{kPa})$ were regarded viable and all arteries in this study satisfied this inclusion criteria. Concentration-effect curves were constructed to NA $(0.1-10 \mu \mathrm{mol} / \mathrm{l})$, with concentration increments at $2 \mathrm{~min}$ intervals. Following repeated washing and recovery $(10 \mathrm{~min})$ arteries were submaximally contracted with NA to achieve approximately $80 \%$ of the maximum response. Endothelial function was assessed by addition of half $\log$ molar increments of ACh at 2 min intervals $\left(10^{-9}-10^{-5}\right.$ $\mathrm{mol} / \mathrm{l})$. A similar protocol was followed to assess endothelium-independent vasodilatation, by assessing relaxation to SNP $\left(10^{-9}-10^{-5} \mathrm{~mol} / \mathrm{l}\right)$.

Assessment of oxidative stress. Tissue and blood samples were taken for analysis of vitamin $\mathrm{E}$ and 8-epi-PGF $2 \alpha$. Liver lobes were removed from the animal, snap frozen in liquid nitrogen and stored at $-70^{\circ} \mathrm{C}$. Blood samples were obtained by cardiac puncture. Samples for 8-epi- $\mathrm{PGF}_{2} \alpha$ and vitamin E were collected into $3.8 \%$ sodium citrate (blood/anticoagulant ratio 9:1) and $14 \mu \mathrm{mol} / \mathrm{l}$ indomethacin (in $5 \%$ sodium bicarbonate). Samples were centrifuged after standing at $4{ }^{\circ} \mathrm{C}$ for $45 \mathrm{~min}$, $\left(2400 \mathrm{~g}, 15 \mathrm{~min}, 4^{\circ} \mathrm{C}\right)$ and aliquots of the supernatant were stored in butylated hydroxytoluene (BHT, $20 \mu \mathrm{mol} / 1$ in ethanol, $-70^{\circ} \mathrm{C}$ ) until analysis [27].

Total (sum of free and esterified) $F_{2}$-isoprostanes in plasma and liver. Due to the limited volumes of plasma available, samples were pooled, and extraction and analysis was then performed in triplicate. Liver measurements were performed in duplicate on samples of tissue from each rat. Plasma $(1 \mathrm{ml})$ was incubated with an aqueous solution of potassium hydroxide $(1 \mathrm{ml}$, $1.0 \mathrm{~mol} / 1,40^{\circ} \mathrm{C}$ for $30 \mathrm{~min}$ ) to hydrolyse esterified $\mathrm{F}_{2}$ isoprostanes. Water $(1 \mathrm{ml})$ was then added and the $\mathrm{pH}$ adjusted with $\mathrm{HCl}$ to $\mathrm{pH}$ 3.0. $\mathrm{PGF}_{2}-\mathrm{d}_{4}(5 \mathrm{ng}$ in $50 \mu$ l ethanol) was added as an internal standard and the sample centrifuged ( $2400 \mathrm{~g}, 5 \mathrm{~min}$ ). The supernatant was applied to a C-18 cartridge $(500 \mathrm{mg})$ preconditioned with methanol and water $(\mathrm{pH} 3.0)$ and the cartridge then washed sequentially with $10 \mathrm{ml}$ water ( $\mathrm{pH} 3.0)$ and acetonitrile /water $(15: 85 \mathrm{v} / \mathrm{v})$ to remove polar material. Lipids were eluted by washing with $5 \mathrm{ml}$ hexane/ethyl acetate/propan-2-ol $(30: 65: 5 \mathrm{v} / \mathrm{v})$. This eluate was then applied to an $\mathrm{NH}_{2}$ cartridge preconditioned with hexane $(5 \mathrm{ml})$ which was then washed sequentially with $10 \mathrm{ml}$ of hexane/ethylacetate $(30: 70$ $\mathrm{v} / \mathrm{v})$, acetonitrile/ water $(90: 10 \mathrm{v} / \mathrm{v})$ and acetonitrile. $\mathrm{F}_{2}$ isoprostanes were eluted from the $\mathrm{NH}_{2}$ cartridge with $5 \mathrm{ml}$ of ethyl actetate/methanol/acetic acid (10:85:5 v/v) and the eluate immediately evaporated under nitrogen at room temperature.

Liver samples $(0.8-1.1 \mathrm{~g})$ were homogenised in ice-cold chloroform/methanol solution (2/1 v/v with BHT, $0.005 \%$ ). Sodium chloride $(0.9 \%)$ was added and the lipid containing chloroform fraction isolated. After solvent evaporation, the lipids were subjected to hydrolysis $\left(30 \mathrm{~min}, 40^{\circ} \mathrm{C}\right.$ with potassium hydroxide, $1.0 \mathrm{~mol} / \mathrm{l}$ ). The sample was then divided for vitamin $\mathrm{E}$ and isoprostane analysis. For isoprostanes, the solution was neutralised with $\mathrm{HCl}(2 \mathrm{ml}, 1.0 \mathrm{~mol} / \mathrm{l})$, acidified to $\mathrm{pH} 1.0$ with $\mathrm{HCl}(0.1 \mathrm{~mol} / \mathrm{l})$, vortex mixed, centrifuged (1118 g) and then filtered. Internal standard $\left(\mathrm{PGF}_{2}-\mathrm{d}_{4}, 5 \mathrm{ng}\right)$ was added and the samples were loaded onto $\mathrm{C}-18$ cartridges as above.

Derivitisation and gas chromatography-mass spectrometry $(G C-M S)$. Pentafluorobenzyl (PFB)-ester was prepared by adding $40 \mu \mathrm{l}$ PFB (10\% in acetone) and $20 \mu \mathrm{l}$ of diisopropylethylamine (DIPEA) (10\% in acetone) to the dried eluate. The vial was then sealed with a Teflon-lined cap and incubated $\left(40^{\circ} \mathrm{C}, 45 \mathrm{~min}\right)$. The solvent was removed under a stream of nitrogen and trimethylsilyl (TMS)-ethers prepared by incubation of the dried sample with $50 \mu \mathrm{l} \mathrm{N}$, O-bis(trimethylsily) trifluoroacetamide (BSTFA) and $5 \mu$ DIPEA (10\% in acetone; $4^{\circ} \mathrm{C}$, overnight). After removing excess solvent with nitrogen, the derivitised sample was reconstituted in iso-octane $(40 \mu \mathrm{l}$, with $10 \%$ BSTFA) and analysed immediately by gas chromatography-mass spectrometry (GC-MS). This was carried out with a Hewlett Packard 5890 gas chromatograph (Bracknell, UK) linked to a VG70SEQ mass spectrometer (Fisons Instruments, Manchester, $\mathrm{UK}$ ), using ammonia as reagent gas. $\mathrm{F}_{2}$ isoprostanes were separated on an SPB-1701 column (30 $\mathrm{m} \times 0.25 \mathrm{~mm}$ i.d $\times 0.25 \mu \mathrm{m} \mathrm{D}$, Supelco, Penn, USA). Samples $(2 \mu \mathrm{l})$ were injected automatically into a temperature programmed Gerstal injector (Thames Chromatography, Maidenhead, UK). The GC oven was programmed from $175-270^{\circ} \mathrm{C}$ at a rate of $30^{\circ} \mathrm{C} / \mathrm{min}$. Quantitative analysis was performed using selected ion monitoring (SIM) of the carboxylate ion [m-181] at $\mathrm{m} / \mathrm{z} 569$ for the $\mathrm{F}_{2}$-isoprostanes and $\mathrm{m} / \mathrm{z} 573$ for $\mathrm{PGF}_{2}-\mathrm{d}_{4}$.

Plasma and liver vitamin E analysis. Liver vitamin E content was assessed in individual samples and plasma concentrations were measured in duplicate from individual plasma samples. $\delta$-tocopherol $(50 \mu \mathrm{l})$ was added, as an internal standard, to $0.5 \mathrm{ml}$ of the treated plasma sample or liver extract (see above). Following addition of water $(0.5 \mathrm{ml})$ and hexane $(1 \mathrm{ml})$ the solution was vortexed and centrifuged $(1118 \mathrm{~g})$. The hexane layer was removed and dried under nitrogen. The extract was reconstituted in $100 \mu \mathrm{l}$ of acetonitrile and transferred to WISP autoinjector vials (Waters, Milford, MA, USA). An aliquot (40 $\mu \mathrm{l}$ ) was injected onto a high pressure liquid chromatograph (HPLC) and detection carried out using fluorescence as described previously [28].

Materials. Chemicals used in this study were: NA (Sanofi Winthrop Ltd, Guildford, Surrey, UK); ACh, SNP, citric acid, trisodium citrate, BHT, indomethacin, metaphosphoric acid, PFB$\mathrm{Br}$ and DIPEA (Sigma-Aldrich Co. Ltd, Poole, Dorset, UK); STZ (gift from Dr. MacLeod, UpJohn Co. Kalamazoo, Mich., USA); Prostaglandin $\mathrm{F}_{2}-\mathrm{d}_{4}$ from Cayman Chemicals (Ann Arbor, MI, USA); Sep-Pak C-18 and aminopropyl $\left(\mathrm{NH}_{2}\right)$ cartridges were from Waters Chromatography (Watford, Herts., UK); BSTFA from Pierce Chemical Company (Rockford, Ill., USA). All other chemicals were obtained from Merck Ltd, Poole, Dorset, UK and were of analytical grade. For the vascular protocols, all concentrations are expressed as their final molar concentrations in the vessel chamber. Supplemented diets were prepared by Special Diet Services, Witham, Essex, UK. The vitamin E content of the standard" rat and mouse no. 1 maintenance diet" ( $\mathrm{R}+\mathrm{M} 1)$ was $75.9 \mathrm{mg} / \mathrm{kg}$, and this was supplemented with $\alpha$-tocopherol acetate as required. Vitamin C (L-ascorbic acid, $99 \%$ ) was obtained from Sigma-Aldrich. Rats were approximately 12 weeks old at the beginning of the study and were obtained from Bantin and Kingman, Universal Ltd (Aldbrough, HuU, UK), UK.

Data calculation and statistical analysis. All values are given as mean \pm SEM. For vascular protocols tension is given as the active wall tension ( $\mathrm{mN} / \mathrm{mm}$ artery length) and the relaxation responses to ACh and SNP were calculated as a percentage of initial preconstriction to NA. For ACh and NA responses the negative $\log$ of the concentration of a drug required to produce $50 \%$ of the maximum response $\left(\mathrm{pEC}_{50}\right)$ was calculated for each artery. Two arteries were used from each animal and mean values calculated. $n$ refers to the number of animals used. The individual $\mathrm{pEC}_{50}$ was calculated using non-linear regression, and the sigmoid equation of a curve fitting program (GraphPad Software, San Diego, CA, USA). Where calculation of $\mathrm{pEC}_{50}$ was not appropriate (for responses to SNP) or where maximal responses were blunted, summary measures were calculated [29]. The summary measure represents the 
Table 1. Plasma glucose concentrations

\begin{tabular}{|c|c|c|c|c|c|c|c|}
\hline & Control & Diabetic & $\begin{array}{l}250 \mathrm{mg} / \mathrm{kg} \\
\text { Vit E }\end{array}$ & $\begin{array}{l}500 \mathrm{mg} / \mathrm{kg} \\
\text { Vit E }\end{array}$ & $\begin{array}{l}\text { Vit E } \\
\text { deficient }\end{array}$ & $\begin{array}{l}250 \mathrm{mg} / \mathrm{kg} \\
\mathrm{H}_{2} \mathrm{O} \text { Vit C }\end{array}$ & $\begin{array}{l}250 \mathrm{mg} / \mathrm{kg} \\
\text { Vit E plus } \\
250 \mathrm{mg} / \mathrm{kg} \\
\mathrm{H}_{2} \mathrm{O} \text { Vit C }\end{array}$ \\
\hline$\pm \mathrm{SEM}$ & 1.4 & 1.2 & 3.6 & 4.5 & 1.7 & 4.7 & 2.2 \\
\hline
\end{tabular}

Data are mean \pm SEM

${ }^{a} p<0.001$ compared to control

Table 2. Effect of vitamin E and C dietary supplementation on responses of small mesenteric arteries to ACh, SNP and NA in STZ-diabetic male Sprague-Dawley rats

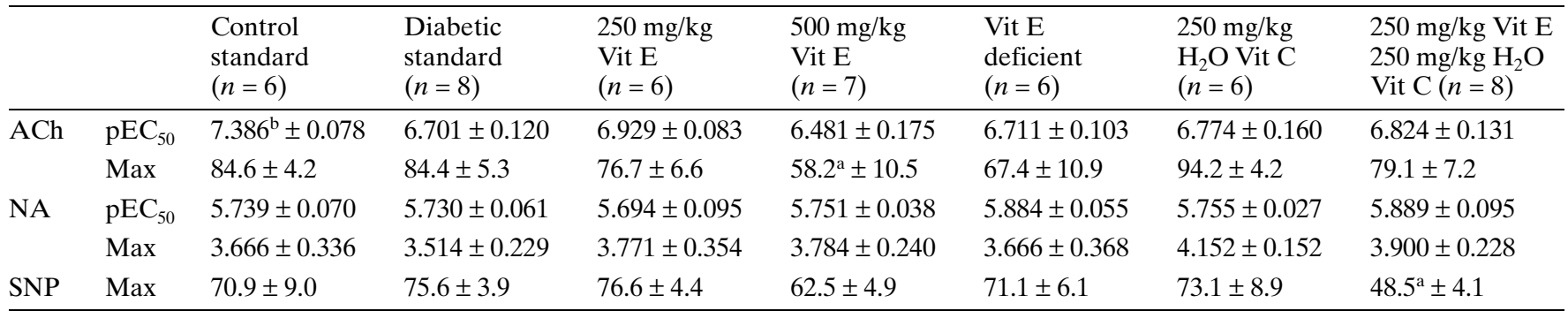

Data are mean \pm SEM. Max, maximum response expressed as \% relaxation to ACh and SNP or as maximum tension (mN/mm) achieved to NA.

${ }^{\mathrm{a}} p<0.05 ;{ }^{\mathrm{b}} p<0.01$ compared to standard diabetic

mean of the values obtained for relaxation at each individual concentration in the concentration response curve. Comparisons were made between mean $\mathrm{pEC}_{50}$ values and summary measures of all groups (InStat GraphPad, GraphPad Software) by ANOVA, using the Dunnett's correction for multiple comparisons with diabetic standard as control. Statistical analysis of tissue and plasma isoprostane and vitamin $E$ data was carried out using the Dunnett's correction for multiple comparisons, or the unpaired Student's $t$-test when data from only two groups was being compared. Significance was assumed at $p=0.05$.

\section{Results}

Plasma glucose was significantly elevated in diabetic animals when compared to controls (Table 1). There was no significant difference in plasma glucose concentrations between any of the treated diabetic groups. While all animals gained weight over the 28 day dietary supplementation period, all the diabetic groups gained significantly less weight than the control group (mean weight of control $363.7 \pm 10.8 \mathrm{~g}$ vs standard diabetic $315 \pm 13.0 \mathrm{~g} ; p<0.05)$. There was no significant difference in weights between diabetic groups on different diets. Food consumption averaged $65.6 \pm 9.24 \mathrm{~g}$ daily and did not differ between control and diabetic groups.
Vascular function in diabetic and control rats on standard diet. Mean arterial internal diameter was $304.1 \pm 6.9 \mu \mathrm{m}(n=103$ arteries $)$. There was no statistical difference in artery diameter between the groups. Preconstricted mesenteric arteries from both control and diabetic rats relaxed in a concentration dependent manner to ACh. The arteries from diabetic animals on the standard diet demonstrated a significant reduction in sensitivity $\left(\mathrm{pEC}_{50}\right)$ to $\mathrm{ACh}$ when compared to controls (Fig. 1a; Table 2). There was no significant difference in the sensitivity of arteries from diabetic and control rats to NA or to SNP (Table 2).

Vascular function in rats on vitamin $E$ deficient diet. There was no observed difference in ACh responses of arteries from the vitamin E-deficient rats when compared to the standard diabetic rats (Fig. 1 a) and no significant difference in responses to SNP (Fig. 1 b) or NA (Table 2).

Vascular function in rats on dietary vitamin E supplementation. Arteries from rats maintained on the $250 \mathrm{mg} / \mathrm{kg}$ vitamin E supplemented diet responded similarly to arteries from diabetic rats on the standard diet. There was no significant difference in response to either ACh (Fig.1a), SNP (Fig.1b) or NA (Table 2). In contrast, arteries from animals fed the $500 \mathrm{mg} / \mathrm{kg}$ vitamin $\mathrm{E}$ chow displayed a further 

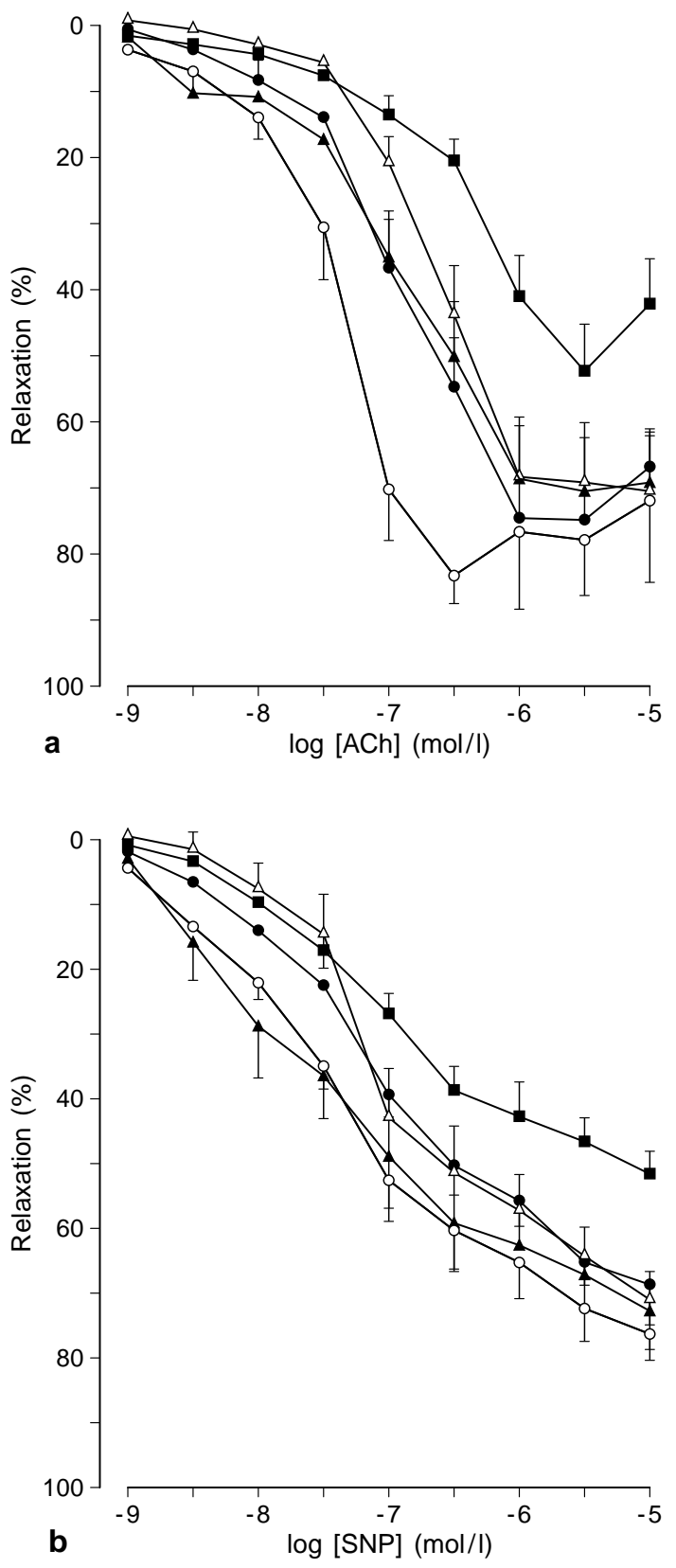

Fig. 1a, b. ACh-induced (a) and SNP-induced (b) relaxation of small mesenteric arteries from STZ-diabetic rats on standard $\operatorname{diet}(\mathbf{O}), 250 \mathrm{mg}$ vitamin $\mathrm{E} / \mathrm{kg}$ chow $(\mathbf{\Delta}), 500 \mathrm{mg}$ vitamin $\mathrm{E} /$ $\mathrm{kg}$ chow $(\square)$, vitamin $\mathrm{E}$ deficient chow $(\triangle)$ and from control non-diabetic rats on standard chow $(O)$

impairment in relaxation to ACh as assessed by summary measure, compared with the diabetic rats on the standard diet (Fig. 1a; Table 2). Responses to SNP appeared impaired when compared to standard (Fig. 1 b) but this did not reach statistical significance. No differences in responses to NA were observed between the groups (Table 2).

Vascular function in diabetic rats on vitamin C supplementation. Vitamin $\mathrm{C}$ supplementation alone did not
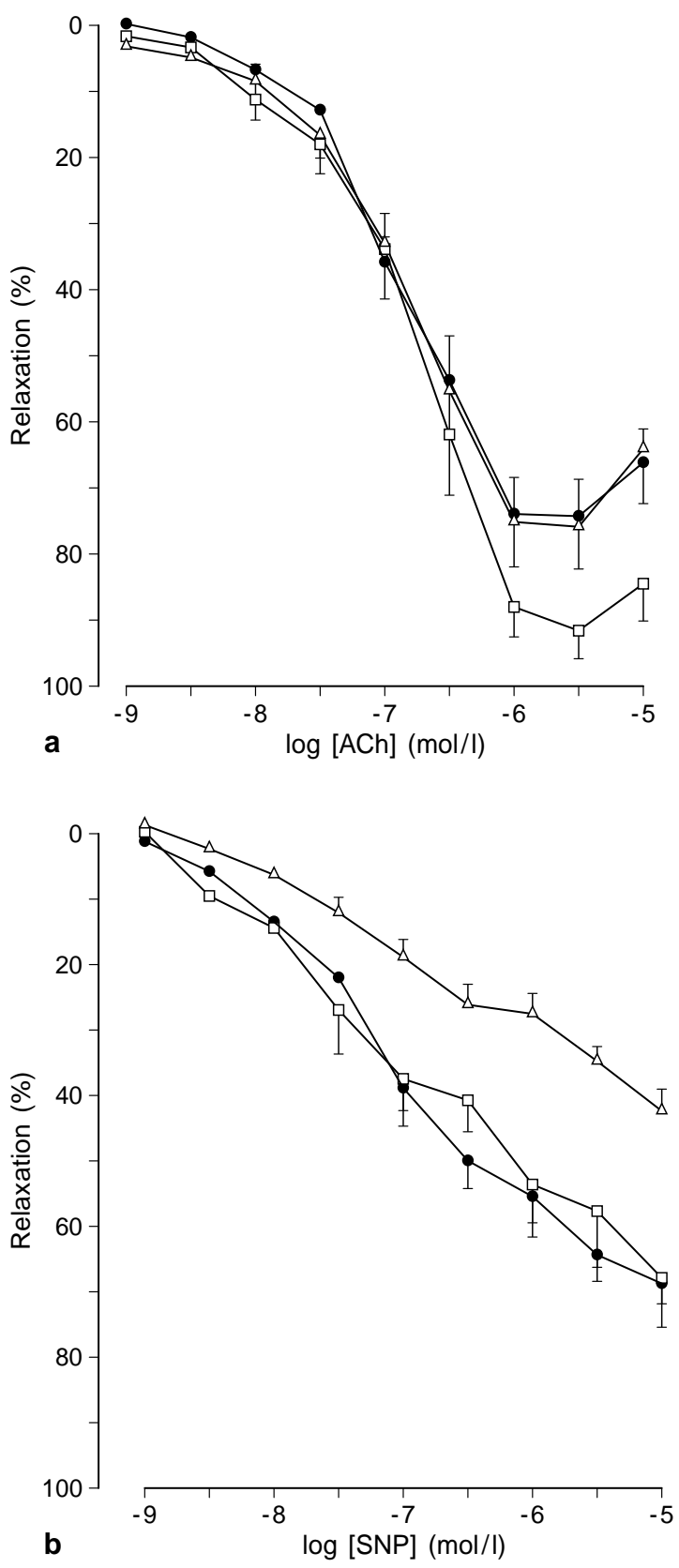

Fig. 2a, b. ACh-induced (a) and SNP-induced (b) relaxation of small mesenteric arteries from STZ-diabetic rats on standard $\operatorname{diet}(\bigcirc), 250 \mathrm{mg}$ vitamin $\mathrm{C} / \mathrm{kg} \mathrm{H}_{2} \mathrm{O}(\square), 250 \mathrm{mg}$ vitamin $\mathrm{E} / \mathrm{kg}$ and $250 \mathrm{mg}$ vitamin $\mathrm{C} / \mathrm{kg} \mathrm{H}_{2} \mathrm{O}(\triangle)$

significantly improve relaxation of arteries to $\mathrm{ACh}$ (Fig. 2a), and had no effect on responses to either SNP (Fig. 2b) or NA (Table 2).

Vascular function in diabetic rats on combined vitamin $E$ and $C$ supplementation. Arteries from rats fed both vitamin $\mathrm{E}$ and $\mathrm{C}$ did not demonstrate an improvement in their responses to ACh (Fig. 2a), and there was no difference in responses to NA when compared to controls (Table 2). However, the relax- 


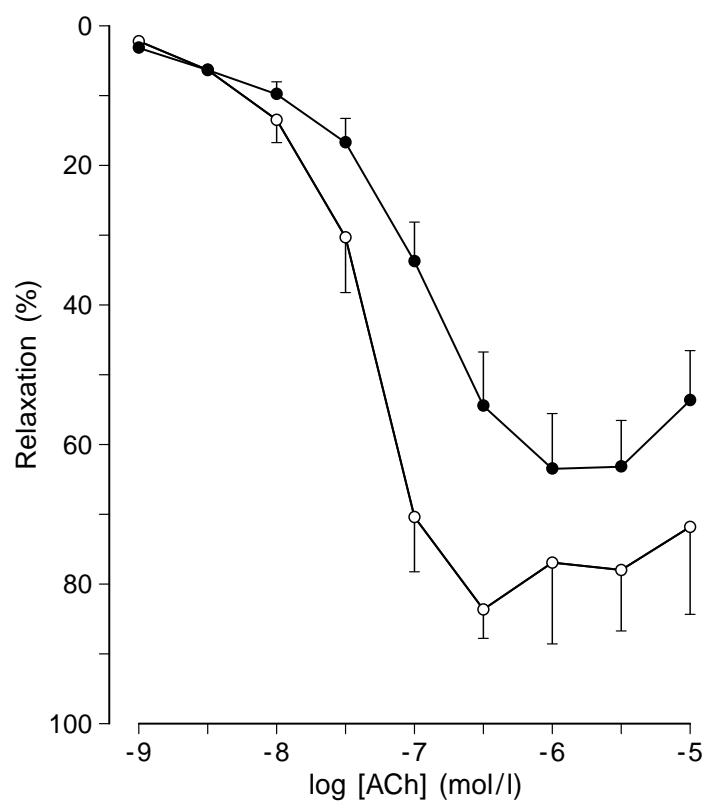

Fig.3. ACh-induced relaxation of small mesenteric arteries from control non-diabetic rats on standard diet $(\bigcirc)$ and on $500 \mathrm{mg} / \mathrm{kg}$ vitamin E supplemented diet

ation to SNP was significantly impaired when compared to standard diabetic rats as assessed by summary measures (Fig. 2b; Table 2).

Vascular function in control rats fed on vitamin $E$ $(500 \mathrm{mg} / \mathrm{kg})$. Control non-diabetic animals fed for 4 weeks on the high vitamin $\mathrm{E}$ diet demonstrated a blunted sensitivity to ACh when compared to control non-diabetic animals fed normal diet $\left(\mathrm{pEC}_{50}\right.$ control non-diabetic rats; $500 \mathrm{mg}$ vitamin $\mathrm{E} / \mathrm{kg} 6.959 \pm 0.136$, $n=6$ vs standard diet $7.386 \pm 0.078, n=6 ; p<0.05$ ) (Fig.3). No changes in responses to NA or SNP were observed.

Liver and plasma vitamin E. Limited samples were available for liver and plasma vitamin $E$ ( $\alpha$-tocopherol) estimation as preference was made for isoprostane analysis. Liver vitamin $\mathrm{E}$ was not different between control non-diabetic rats and diabetic rats on a vitamin $\mathrm{E}$ deficient diet (1.98 \pm 0.08 in controls, $n=4$ vs $1.70 \pm 0.30 \mu \mathrm{g} / \mathrm{g}$ in deficient, $n=3$; NS). Vitamin $\mathrm{E}$ estimations were not carried out for intermediate supplementation doses, but liver content was significantly raised in rats on $500 \mathrm{mg} / \mathrm{kg}$ vitamin $\mathrm{E}(13.33 \pm 1.05 \mu \mathrm{g} /$ $\mathrm{g}, n=3 ; p<0.01)$ when compared to non-diabetic controls. There was also a significant increase in plasma vitamin E concentration in $500 \mathrm{mg} / \mathrm{kg}$ vitamin $\mathrm{E}$ fed rats when compared to diabetic rats on standard chow $(12.62 \pm 0.53$ in $500 \mathrm{mg} / \mathrm{kg}$ vitamin E, $n=4$ vs $1.68 \pm$ $0.32 \mu \mathrm{mol} / \mathrm{l}$ in standard diabetic, $n=3 ; p<0.0001)$.

Plasma concentrations of 8 -epi-PGF $F_{2 \alpha}$. The plasma concentration of 8 -epi-PGF $\mathrm{PG}_{2 \alpha}$ was $0.58 \pm 0.06 \mathrm{nmol} / \mathrm{l}$
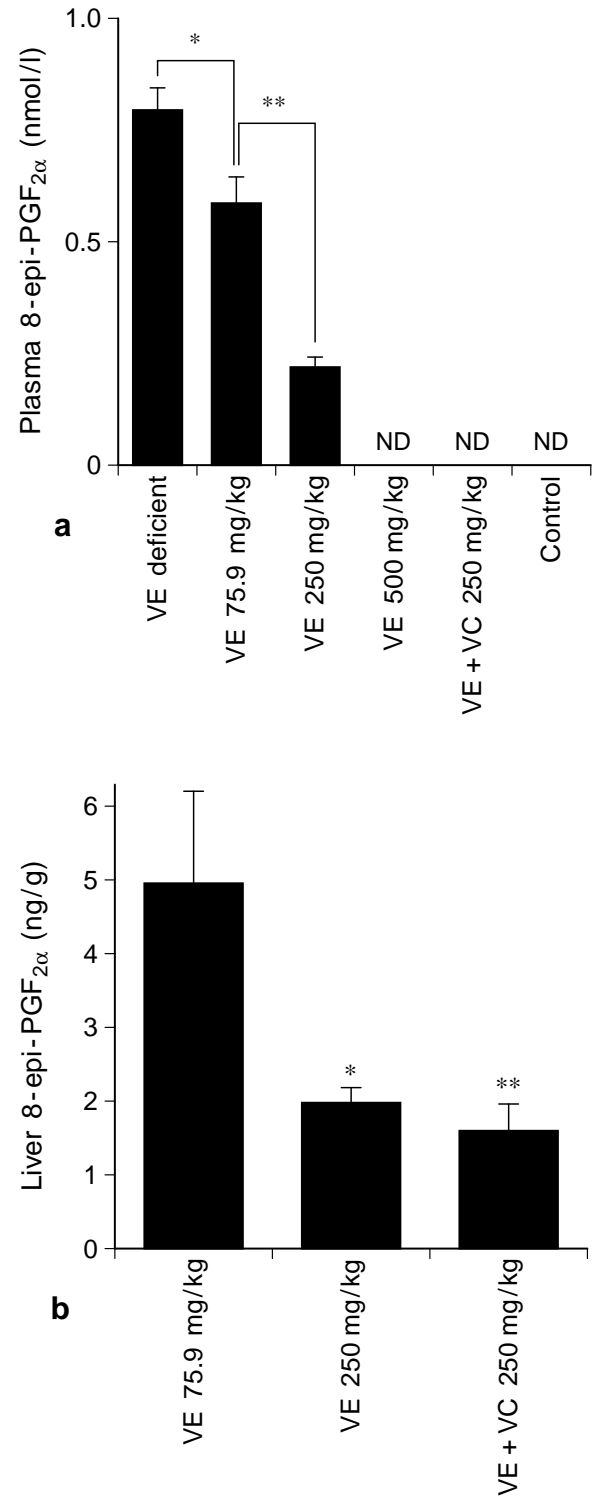

Fig. 4. a) Plasma concentration of 8 -epi- $\mathrm{PGF}_{2 \alpha}$ from vitamin $\mathrm{E}$ and vitamin $\mathrm{C}$ treated STZ-rats. b) Liver content of 8-epiPGF2 $\alpha$ from vitamin $\mathrm{E}$ and vitamin $\mathrm{C}$ treated STZ-rats. ND refers to non-detectable levels of 8 -epi-PGF $2 \alpha$ in sample. $* p<0.05, * * p<0.01$

in plasma from diabetic rats on standard chow $(n=3)$ but was below the level of detection $(0.03$ $\mathrm{nmol} / \mathrm{l})$ in plasma from control non-diabetic rats $(n=4)$. The plasma concentration of 8 -epi-PGF ${ }_{2 \alpha}$ was significantly greater in rats on a vitamin $\mathrm{E}$ deficient diet $(0.79 \pm 0.05 \mathrm{nmol} / \mathrm{l}, n=5$ vs standard diabetic; $p<0.05)$ and there was a significant decrease in plasma concentration $(0.22 \pm 0.02 \mathrm{nmol} / \mathrm{l}, n=3$; $p<0.01)$ of the $250 \mathrm{mg} / \mathrm{kg}$ vitamin E treated group when compared to that of the standard diabetic group. Plasma 8-epi-PGF ${ }_{2 \alpha}$ was below the detection limit of $0.03 \mathrm{nmol} / 1$ in those animals treated with $500 \mathrm{mg} / \mathrm{kg}$ vitamin $\mathrm{E}(n=4)$ or a combination of vitamin $\mathrm{E}$ and $\mathrm{C}(n=6)$ (Fig. $4 \mathrm{a})$. 
Liver content of 8-epi-PGF $F_{2 \alpha}$. There was a reduction of 8 -epi-PGF ${ }_{2 \alpha}$ in the livers of the $250 \mathrm{mg} / \mathrm{kg}$ vitamin $\mathrm{E}$ fed diabetic rats compared with those on standard diet $(2.00 \pm 0.20$ in $250 \mathrm{mg} / \mathrm{kg}$ vitamin $\mathrm{E}$, $n=4$ vs $4.96 \pm 1.25 \mathrm{ng} / \mathrm{g}$ tissue in standard diabetic, $n=4 ; p<0.05)$. 8-epi-PGF $2 \alpha$ levels were also decreased in rats on combined vitamin $\mathrm{E}$ and $\mathrm{C}$, when compared to those on standard diet $(1.61 \pm 0.37 \mathrm{ng} / \mathrm{g}$ tissue in vitamin $\mathrm{E}+\mathrm{C}$ group, $n=7 ; p<0.01$ ) (Fig. 4b).

\section{Discussion}

This study reports that the defect in ACh-induced endothelium-dependent relaxation in small mesenteric arteries from the STZ-rat, demonstrated in this and previous studies [1], was not reversed by vitamin $\mathrm{E}$ dietary supplementation. Indeed, the higher dose of vitamin E (500 mg/kg diet) caused further attenuation of the vasodilatory response to ACh. This occurred despite the concomitant fall in levels of the isoprostane 8-epi-PGF ${ }_{2 \alpha}$ in plasma and liver, indicative of decreased oxidative stress. These data strongly suggest that vascular dysfunction in this animal model of diabetes is unlikely to be mediated by oxidative stress. In addition, this study is the first to use isoprostanes as markers of oxidative stress in the STZ-diabetic rat model of IDDM and to show that elevated plasma and tissue levels are reversed by antioxidant supplementation. To our knowledge only one study [20] has shown previously that 8 -epi- $\mathrm{PGF}_{2 \alpha}$ concentration may be reversed by antioxidant supplementation.

Two studies have previously reported beneficial effects of dietary vitamin $\mathrm{E}$ supplementation in the STZ-rat model of uncontrolled IDDM although both used a higher dose. These showed improvement of coronary vessel endothelial function and blood flow [23], and of ACh-induced dilatation in aorta [5]. Inadequate supplementation was not likely to account for the lack of improvement of vascular function in this study as both liver and plasma vitamin $\mathrm{E}$ increased significantly after supplementation. An alternative, but we consider unlikely, explanation for the variance of these results to others could lie in the relative contribution of different dilator agents to ACh-induced relaxation in conduit and small arteries, such as endothelium-derived hyperpolarising factor, $\mathrm{NO}$, and $\mathrm{PGI}_{2}$.

In common with the present study in which vitamin E supplementation further impaired vascular endothelial function in the diabetic rats, deleterious effects of vitamin $E$ have been reported in a study of hypercholesterolaemic rabbits [30]. In these animals, defective ACh-mediated endothelium-dependent relaxation was present and low dose $\alpha$-tocopherol improved, but high dose $\alpha$-tocopherol further impaired the ACh-mediated relaxation of the aorta. Furthermore, vascular function (determined by forearm venous occlusion plethysmography) [31] did not improve in hypercholesterolaemic patients on supplements of $400 \mathrm{mg}$ vitamin E/day over 8 weeks. In both studies, despite the variable vascular responses to vitamin E supplementation, a decreased susceptibility of plasma-derived LDL to copper-induced oxidation in response to $\mathrm{Cu}^{2+}$ ions indicated effective reduction of oxidative stress.

Few of the earlier studies of vitamin E supplementation in animals determined whether it affects endothelial function in controls, but the control rats fed on the higher of the vitamin E supplemented diets in this study developed a defect in endothelium-dependent relaxation, the shift in the response being of similar magnitude to that observed in the diabetic rats fed the same diet. Excessive antioxidant treatment per se may therefore be deleterious to vascular function in normal rats.

The rationale for the use of combined vitamin $\mathrm{E}$ and $\mathrm{C}$ in one of the groups of diabetic rats lies in the vital role that vitamin $\mathrm{C}$ is considered to play in the regeneration of $\alpha$-tocopherol [25]. Plasma 8-epi$\mathrm{PGF}_{2 \alpha}$ concentrations in diabetic animals on the combined vitamin $\mathrm{E}(250 \mathrm{mg} / \mathrm{kg})$ plus $\mathrm{C}$ diet were decreased to a level significantly lower than in the $250 \mathrm{mg} / \mathrm{kg}$ vitamin $\mathrm{E}$ supplemented rats, which implies that recycling of vitamin $\mathrm{E}$ by vitamin $\mathrm{C}$ had indeed occurred. Despite this, a significant impairment in relaxation to SNP was observed in arteries from combined vitamin $\mathrm{E}$ and $\mathrm{C}$ treated rats and no improvement in ACh-induced relaxation was observed in either combined vitamin $\mathrm{E}$ plus $\mathrm{C}$ or vitamin $\mathrm{C}$ alone treated diabetic rats. Previous studies of vitamin $C$ supplements on diabetic vascular dysfunction are few, but minimal benefit of vitamin $\mathrm{C}$ supplementation has been reported in a study of peripheral nerve and neurovascular function in diabetic rats [24] together with an additive effect of combined vitamin $\mathrm{E}$ and $\mathrm{C}$ in the prevention of reduced motor nerve conduction velocity. A possible explanation for the lack of response to vitamin $\mathrm{C}$ alone in the STZ-rat could be that endogenous synthesis of the vitamin is sufficient to prevent depletion. However, the STZ-rat has been reported to be ascorbic acid deficient [10] and would, theoretically, benefit from supplementation.

The mechanism behind the deleterious action of vitamin $E$ in these studies is unclear, but as the defect lay at the level of both endothelium-dependent and independent relaxation, it may represent excessive NO degradation. NO (itself a free radical) could be directly scavenged by the high concentrations of $\alpha$-tocopherol present in the plasma membrane of vascular smooth muscle cells of the treated animals $[32,33]$. The further impairment of vascular function in rats on the combined vitamin $\mathrm{E}$ and $\mathrm{C}$ diet may reflect 
the increased availability of reduced vitamin $\mathrm{E}$ to quench NO. In the diabetic rabbit aorta [34] but not in the diabetic rat small mesenteric artery [3], synthesis of constrictor prostanoids counteracts ACh-induced relaxation. In the present study we did not include the use of cyclooxygenase inhibitors and therefore we cannot exclude the possibility that vitamin $\mathrm{E}$ may have led to de novo synthesis of constrictor prostanoids in response to ACh.

The relevance of the effects of antioxidant supplementation in rat mesenteric arteries to responses in other vascular beds and other species must be considered. Since the defect of ACh-induced relaxation is common to other vascular beds of the STZ rat [3-5] and to arteries of the subcutaneous circulation in diabetic subjects [2] we consider that the data in this study may be pertinent to other circulations, and indeed to diabetic patients.

In conclusion, although antioxidant therapy ameliorates oxidative stress, it does not improve vascular endothelial dysfunction in the small mesenteric arteries of the STZ diabetic rat. At high doses, vitamin E may have deleterious effects in the vasculature of normal animals and this observation should be of concern in any study in which antioxidant therapy is employed. Vitamin E metabolism in disease and the question of dose are obviously crucial issues and need further investigation before it can be recommended with confidence as a dietary supplement.

Acknowledgements. We thank the British Heart Foundation for supporting this study and Professor A. Mallet for use of the UMDS Mass Spectrometry facilities.

\section{References}

1. Poston L, Taylor PD (1995) Endothelium-mediated vascular function in insulin-dependent diabetes mellitus. Clin Sci 88: 245-255

2. McNally PG, Watt PAC, Rimmer T, Burden AC, Hearnshaw JR, Thurston H (1994) Impaired contraction and endothelium-dependent relaxation in isolated resistance vessels from patients with insulin-dependent diabetes mellitus. Clin Sci 87: 31-36

3. Taylor PD, McCarthy AL, Thomas CR, Poston L (1992) Endothelium-dependent relaxation and noradrenaline sensitivity in mesenteric resistance arteries of streptozotocininduced diabetic rats. Br J Pharmacol 107: 393-399

4. Taylor PD, Graves JE, Poston L (1995) Selective impairment of acetylcholine-mediated endothelium-dependent relaxation in isolated resistance arteries of the streptozotocin-induced diabetic rat. Clin Sci 88: 519-524

5. Keegan A, Walbank H, Cotter MA, Cameron NE (1995) Chronic vitamin $\mathrm{E}$ treatment prevents defective endothelium-dependent relaxation in diabetic rat aorta. Diabetologia 38: 1475-1478

6. Tribe RM, Thomas CR, Poston L (1998) Flow-induced dilatation in isolated resistance arteries from control and streptozotocin-diabetic rats. Diabetologia 41: 34-39
7. Cohen RA (1993) Dysfunction of vascular endothelium in diabetes mellitus. Circulation 87:V67-V76

8. Tribe RM, Poston L (1996) Oxidative stress and lipids in diabetes: a role in endothelium vasodilator dysfunction? Vascular Medicine 1: 195-206

9. Karpen CW, Cataland S, O'Dorisio TM, Panganamala RV (1985) Production of 12-hydroxyeicosatetraenoic acid and Vit E status in platelets from type I human diabetic subjects. Diabetes 34: 526-531

10. McLennan S, Yue DK, Fisher E, Capogreco C, Heffernan S, Ross GR, Turtle JR (1988) Deficiency of ascorbic acid in experimental diabetes. Relationship with collagen and polyol pathway abnormalities. Diabetes 37: 359-361

11. Morel DW, Chisolm GM (1989) Antioxidant treatment of diabetic rats inhibits lipoprotein oxidation and cytotoxicity. J Lipid Res 30: 1827-1834

12. Krempf M, Ranganathan S, Ritz P, Morin M, Charbonnel B (1991) Plasma Vit A and E in type 1 (insulin-dependent) and type 2 (non-insulin dependent) adult diabetic patients. Int J Vitam Nutr Res 61: 38-42

13. Thompson KH, Godin DV, Lee M (1992) Tissue antioxidant status in streptozotocin-induced diabetes in rats. Effects of dietary manganese deficiency. Biol Trace Elem Res 35: 213-224

14. Wolff SP (1993) Diabetes mellitus and free radicals. $\mathrm{Br}$ Med Bull 49: 642-652

15. Jacobs M, Plane F, Bruckdorfer KR (1990) Native and oxidised low density lipoproteins have different inhibitory effects on endothelium-derived relaxing factor in the rabbit aorta. Br J Pharmacol 100: 21-26

16. Liao JK, Shin WS, Lee WY, Clark SL (1995) Oxidized lowdensity lipoprotein decreases the expression of endothelial nitric oxide synthase. J Biol Chem 270: 319-324

17. Morrow JD, Hill KE, Burk RF, Nammour TM, Badr KF, Roberts LJ II (1990) A series of prostaglandin $F_{2}$ like compounds are produced in vivo by humans by a non-cyclooxygenase, free radical catalyzed mechanism. Proc Natl Acad Sci USA 87: 9383-9387

18. Morrow JD, Roberts LJ (1996) The isoprostanes. Current knowledge and directions for future research. Biochem Pharmacol 51: 1-9

19. Gopaul NK, Anggard EE, Mallet AI, Betteridge DJ, Wolff SP, Nourooz-Zadeh J (1995) Plasma 8-epi-PGF 2 $\alpha$ levels are elevated in individuals with non-insulin dependent diabetes mellitus. FEBS Lett 368: 225-229

20. Reilly M, Delanty N, Lawson JA, Fitzgerald GA (1996) Modulation of oxidant stress in vivo in chronic cigarette smokers. Circulation 94: 19-25

21. Kromer BM, Tippins JR (1996) Coronary artery constriction by the isoprostane 8-epi prostaglandin $\mathrm{F}_{2} \alpha$. Br J Pharmacol 119: 1276-1280

22. Stephens NG, Parsons A, Schofield PM, Kelly F, Cheeseman K, Mitchinson MJ (1996) Randomised controlled trial of vitamin $\mathrm{E}$ in patients with coronary disease: Cambridge Heart Antioxidant Study (CHAOS). Lancet 347: 781-786

23. Rosen P, Ballhausen T, Bloch W, Addicks K (1995) Endothelial relaxation is disturbed by oxidative stress in the diabetic rat heart: influence of tocopherol as antioxidant. Diabetologia 38: 1157-1168

24. Cotter MA, Love A, Watt MJ, Cameron NE, Dines KC (1995) Effects of natural free radical scavengers on peripheral nerve and neurovascular function in diabetic rats. Diabetologia 38: 1285-1294

25. Packer JE, Slater TF, Willson RL (1979) Direct observation of a free radical interaction between vitamin $\mathrm{E}$ and vitamin C. Nature 278: 738-739 
26. Mulvany MJ, Halpern W (1977) Contractile properties of small arterial resistance vessels in spontaneously hypertensive and normotensive rats. Circ Res 41: 19-26

27. Nourooz-Zadeh J, Gopaul NK, Barrow S, Mallet AI, Anggard EE (1995) Analysis of $F_{2}$-isoprostanes as indicators of non-enzymatic lipid peroxidation in vivo by gas chromatography-mass spectrometry: development of a solid-phase extraction procedure. J Chromatogr B Biomed Appl 667: 199-208

28. Gopaul NK, Nourooz-Zadeh J, Mallet AI, Anggard EE (1994) Formation of PGF2-isoprostanes during the oxidative modification of low density lipoprotein. Biochem Biophys Res Comm 200: 338-343

29. Matthews JNS, Altman DG, Campbell MJ, Royston P (1990) Analysis of serial measurements in medical research. BMJ 300: 230-235

30. Keaney JF Jr., Gaziano JM, Xu A et al. (1994) Low-dose alpha-tocopherol improves and high-dose alpha-toco- pherol worsens endothelial vasodilator function in cholesterol-fed rabbits. J Clin Invest 93: 844-851

31. McDowell IF, Brennan GM, McEneny J et al. (1994) The effect of probucol and vitamin $\mathrm{E}$ treatment on the oxidation of low-density lipoprotein and forearm vascular responses in humans. Eur J Clin Invest 24: 759-765

32. de Groot H, Hegi U, Sies H (1993) Loss of $\alpha$-tocopherol upon exposure to nitric oxide or the sydnonimine SIN-1. FEBS Lett 315: 139-142

33. Gorbunov NV, Osipov AN, Sweetland MA, Day BW, Elsayed NW, Kagan VE (1996) NO-redox paradox: direct oxidation of $\alpha$-tocopherol and $\alpha$-tocopherol-mediated oxidation of ascorbate. Biochem Biopys Res Commun 219: 835841

34. Tesfamariam B, Jakubowski JA, Cohen RA (1989) Contraction of diabetic rabbit aorta caused by endothelium-derived $\mathrm{PGH}_{2}-\mathrm{TxA}_{2}$. Am J Physiol 257:H1327-H1333 